\title{
Examining the object-based and pixel-based image analyses for developing stand volume estimator model
}

\author{
Dwi Putra Apriyanto, I Nengah Surati Jaya, Nining Puspaningsih \\ Department of Forest Management, Bogor Agricultural University, Indonesia
}

\begin{tabular}{l}
\hline \hline Article Info \\
\hline Article history: \\
Received Oct 1, 2018 \\
Revised Dec 10, 2018 \\
Accepted Jan 25, 2019 \\
\hline
\end{tabular}

\section{Keywords:}

Estimator model Index vegetation Mean-shift algorithm Object-based

Pixel-based

\begin{abstract}
In the last two decades there has been significant leap on the spatial resolution of the satellite digital images which may be very useful for estimating stand parameter required for forest as well as environment management. This paper describes development of stand volume estimator models using SPOT 6 panchromatic and multispectral images with an objectbased digital image analysis (OBIA) and conventional pixel-based approaches. The data used include panchromatic band with $1.5 \mathrm{~m}$ spatial resolution, and multispectral band with6m spatial resolution. The proposed OBIA technique with mean-shift algorithm was functioned to derive a canopy cover variable from the fusion of the panchromatic and multispectral, while the pixel-based vegetation index was used to develop model with an original pixel-size of $6 \mathrm{~m}$. The estimator models were established based on 65 sample plots both measured in the field and images. The study found that the OBIA provides more accurate identification with Kappa Accuracy (KA) of $71 \%$ and Overall Accuracy (OA) of $86 \%$. The study concluded that the best stand volume estimation model is the model that developed from the canopy cover $(\mathrm{C})$ derived from OBIA i.e., $\mathrm{v}=13.47 \mathrm{e}^{0.032 \mathrm{C}}$ with mean deviation of only $0.92 \%$, better than the model derived from conventional pixel-based approach, i.e., $v=0.0000067 \mathrm{e}^{16.48 \mathrm{TNDVI}}$ with a mean deviation of $5.37 \%$.
\end{abstract}

Copyright ( 2019 Institute of Advanced Engineering and Science. All rights reserved.

\section{Corresponding Author:}

I Nengah Surati Jaya,

Department of Forest Management,

Bogor Agricultural University, Jl. Raya Dramaga, Bogor 16680, West Java, Indonesia.

Email: ins-jaya@apps.ipb.ac.id

\section{INTRODUCTION}

Development of stand-volume models based on remote sensing data usually involves measurements of independent variables through visual interpretation method on the image [1,2]. The visual interpretation mainly relies more on the capability of interpreters that are quite varied from person to person, depending on the their skill and experiences that may provide inconsistence results. So that, to reduce inconsistence in performing measurement and interpretation the images, then it is necessary to develop a more quantitative approach that apply automatic and / or semi-automatic methods.

One of commonly used quantitative approaches are the pixel-based and/or the object-based algorithms. In the classifying medium resolution images, the pixel-based image is widely used and proven to be more practical and accurate. However, detection and identification of objects in high and very high resolution images, approaches that are only based on the pixel values tend to be less accurate, because most reflectance and radiation objects are less sensitive to the dimensions of the object. Some studies, proven that the object-based approach may provide better accuracy [3-5].

In the last two decades, in line with the availability of high and very high resolution images and digital image analysis techniques, classification of high and very high resolution images have led to the use of the object-based algorithms [6,7]. This object-based classification method uses three main parameters as 
object detectors, namely spatial radius, range radius, and minimum region size. This classification method performs detection and delineation, not only based on pixel but also based on object segmentation. Image segmentation techniques using the algorithm Mean-shift [8-10] have been used in several forest resource studies, such as the use of unmanned imagery in the inventory of nipah vegetation with overall and kappa accuracy of $76.6 \%$ and $55.7 \%$ [11] and environmental management monitoring [12]. Detection of land use changes images Synthetic Aperture Radar (SAR) with mean shifts shows better detection and identification capabilities than classic log ratios [13], detection of forest changes due to storms using OBIA [14].

Recently, three are a lot of high resolution images available for forest measurement. However, only few studies were conducted by using quantitatives approach. The segmentation method with the algorithm mean shift may increase the accuracy value by $40.9 \%$ when compared with other methods such as region growing, and k-means [15], the mean shift algorithm also reduces work time by $40 \%$ when compared to the algorithm kmeans [16].

In this study, there are several research questions that need to be studied, namely:

a) What is the reliability of pixel-based and object-based approaches for forest cover detection in lowland forests?; and

b) How do the performance of classification using the combination of pixel-based and object-based approaches, particularly on estimating stand stock?.

c) Which combination of object-based method parameter provide the most accurate assessment for detecting stand variables?

The main objective of this study is to develop a mathematical model and test its reliability base on pixel-based and object-based approaches, as well as to find out the best estimate of stand volume model using very high resolution satellite imagery.

\section{RESEARCH METHOD}

\subsection{Site describtion}

The study site was located in Bintuni Bay District, West Papua Province, while data processing was carried out in the Laboratory Remote Sensing and Geographic Information System (GIS), Forest Planning Division, Department of Forest Management, Faculty of Forestry, Bogor Agricultural University, from December 2016 to August 2018. The geographical location of the study site is located at coordinates between $132^{\circ} 59^{\prime}-133^{\circ} 46^{\prime} \mathrm{BT}$ and $01^{\circ} 26-02^{\circ} 11^{\prime} \mathrm{LS}$ (Figure 1).

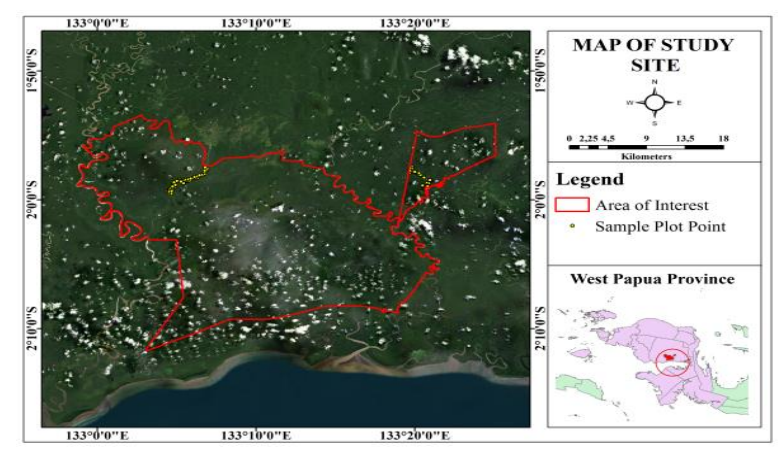

Figure 1. Map of research locations

\subsection{Data and softwere}

Main data used in the study were the SPOT 6 image having spatial resolution of 1.5 meters and 6 meters, field measurements consisted of diameter at breast high (dbh), tree height, spesies name and regeneration. During data processing and data analysis, some software's were applied, namely the ERDAS Imagine Ver. 14 for image analysis, Microsoft Excel 2007 for performing statistical analysis, and QGIS 2.18 which was equipped with tool Orfeo Toolbox for performing spatial operation and segmentation. Measurement of stand dimensions used phi-band, distance meter, compass, Global Positioning System (GPS), plastic/mine rope, Suunto, flagging tape, tally sheet, writing instruments, and digital cameras.

The SPOT 6 multispectral image consisted of Red, Green, and Blue bands (band 321) which may produce natural colors having spatial resolution of 6 meters. The panchromatic band of SPOT6 image have spatial resolution of 1.5 meters. During the analysis, SPOT6 image having 6 meter spatial resolution was pansharpened using the Brovey Transformation. The Brovey's method is the most popular method for

Examining the object-based and pixel-based image analyses for developing stan... (Dwi Putra Apriyanto) 
combining two types of images spatial resolution [17] developed by an American scientist to improve the visual appearance of an image.

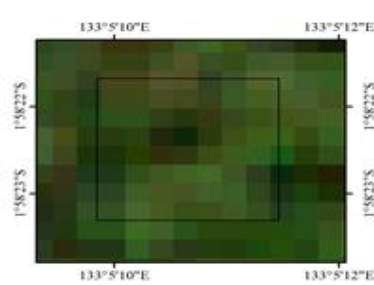

(a)

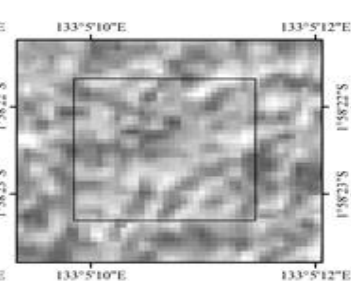

(b)

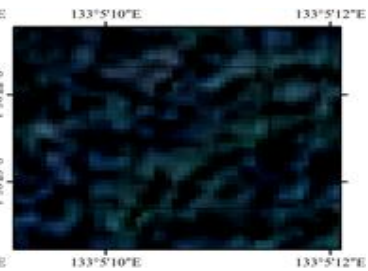

(c)

Figure 2. (a) SPOT 6 multi-spectral image, (b) panchromatic, (c) pansharperning

\subsection{Research procedure}

\subsubsection{Pre processing image}

Prior to any further analysis, several pre-processing activities were performed, namely geometric correction, image-sharpening, visual interpretation process (on screen digitizing) to identify the land cover class (forest, road, and body of water) and defining general description of canopy cover class.

\subsubsection{Field measurement}

For dry land forest, measurement of stand parameters was carried out by measuring all tree size, starting from the small size trees $(\mathrm{dbh} \geq 20 \mathrm{~cm})$ up to the large size trees having dbh larger than $30 \mathrm{~cm}$. The small size tree were measured within the sub-plot of $25 \mathrm{~m}$ x $25 \mathrm{~m}$, while the large tree was measured within $50 \mathrm{~m}$ x $50 \mathrm{~m}$ plot. The total number of sample plots measured in the field was 65 plots, where 33 sample plots were used to establish a model and the rest of 32 sample plots were used on model validation process. The all sample plots was selected purposively based on the characteristics of the image and accessibility consideration.

Furthermore, the volume of each trees was calculated by using the equation published on the monograph of allometric models issued by the Forestry Research and Development Agency in 2012. The applied model was $\mathrm{Vol}\left(\mathrm{m}^{3}\right)=0.000309421 \mathrm{dbh}^{2.13873}$ having $\mathrm{R}^{2}$ of $93 \%$ [18].

\subsubsection{Vegetation index transformation}

On pixel-based approach, the original band were transformed into several indices, by applying several combination of spectral bands, such as green, red and near infrared (NIR). Vegetation index is optical measurement of greenness of vegetation canopy, composite properties of leaf chlorophyll, leaf area, structure and cover of vegetation canopy. In this study, several vegetation indices applied are as follows:

a. Soil Adjusted Vegetation Index (SAVI)

$$
\mathrm{SAVI}=\frac{(\mathrm{NIR}-\mathrm{RED}) *(1+\mathrm{L})}{(\mathrm{NIR}+\mathrm{RED}+\mathrm{L})}
$$

b. Difference Vegetation Index (DVI)

$$
\mathrm{DVI}=\mathrm{NIR}-\mathrm{RED}
$$

c. Normalized Difference Vegetation Index (NDVI)

$$
\mathrm{NDVI}=\frac{\mathrm{NIR}-\mathrm{RED}}{\mathrm{NIR}+\mathrm{RED}}
$$

d. Vegetation Index ratio (RVI)

$$
\mathrm{RVI}=\mathrm{RED} / \mathrm{NIR}
$$

e. Red Green Index (RGI)

$$
\mathrm{RGI}=\frac{\text { GREEN }- \text { RED }}{\text { GREEN }+ \text { RED }}
$$


f. Renormalized Difference Vegetation Index (RDVI)

$$
\text { RDVI }=\frac{\text { NIR-RED }}{\text { SQRT }(\text { RED NIR })}
$$

g. Transformed Difference Vegetation Index (TNDVI)

$$
\text { TNDVI }=\left[\frac{\text { NIR-RED }}{\text { NIR }+ \text { RED }}+\mathbf{C}\right]^{1 / 2}
$$

where $\mathrm{L}=$ ground background adjustment factor in canopy; $\mathrm{C}=$ constant $(0.5)$.

\subsubsection{Object-based image classification}

The process of segmentation is an initial process of object-based images or also called object base image analysis (OBIA). In image segmentation, pixels were mapped into a color space (filtering) and grouped (clustering), where each cluster describes a homogeneous area (similar spectral values and spatial characteristics) in the image. In this study, the segmentation process uses mean-shift algorithms with parameters spatial radius, radius ranges, and minimum size regions. Spatial radius (Hs) is a parameter that has a function to control distance, measured by a number of pixels. Spatial radius will group a number of pixels into one segment or one object, while range radius $(\mathrm{Hr})$ is a segmentation parameter that matches the spectral value of each pixel. The radius range refers to spectral variability (distance in n-dimensional spatial space) to group a number of pixels into one segment. Furthermore, it is also defined that the minimum region size (M) is a parameter associated with the minimum size of the number of pixels that make up a single object. Objects that have a number of pixels below the parameter value will be combined with the closest object. This study examined 27 combinations of means of parameter shift in each cluster to obtain canopy cover values and vegetation gaps (Table 1).

\begin{tabular}{|c|c|c|c|c|c|c|c|c|c|}
\hline No & Code Combination & $\mathrm{Hs}$ & $\mathrm{Hr}$ & $\mathrm{M}$ & No & Code Combination & $\mathrm{Hs}$ & $\mathrm{Hr}$ & $\mathrm{M}$ \\
\hline 1 & $\mathrm{~K}-01$ & 2 & 21 & 4 & 15 & $\mathrm{~K}-15$ & 5 & 28 & 49 \\
\hline 2 & $\mathrm{~K}-02$ & 2 & 21 & 20 & 16 & K-16 & 5 & 35 & 4 \\
\hline 3 & $\mathrm{~K}-03$ & 2 & 21 & 49 & 17 & $\mathrm{~K}-17$ & 5 & 35 & 20 \\
\hline 4 & K-04 & 2 & 28 & 4 & 18 & $\mathrm{~K}-18$ & 5 & 35 & 49 \\
\hline 5 & $\mathrm{~K}-05$ & 2 & 28 & 20 & 19 & $\mathrm{~K}-19$ & 11 & 21 & 4 \\
\hline 6 & K-06 & 2 & 28 & 49 & 20 & $\mathrm{~K}-20$ & 11 & 21 & 20 \\
\hline 7 & K-07 & 2 & 35 & 4 & 21 & $\mathrm{~K}-21$ & 11 & 21 & 49 \\
\hline 8 & $\mathrm{~K}-08$ & 2 & 35 & 20 & 22 & $\mathrm{~K}-22$ & 11 & 28 & 4 \\
\hline 9 & K-09 & 2 & 35 & 49 & 23 & $\mathrm{~K}-23$ & 11 & 28 & 20 \\
\hline 10 & K - 10 & 5 & 21 & 4 & 24 & $\mathrm{~K}-24$ & 11 & 28 & 49 \\
\hline 11 & K-11 & 5 & 21 & 20 & 25 & $\mathrm{~K}-25$ & 11 & 35 & 4 \\
\hline 12 & K-12 & 5 & 21 & 49 & 26 & $\mathrm{~K}-26$ & 11 & 35 & 20 \\
\hline 13 & K-13 & 5 & 28 & 4 & 27 & K- 27 & 11 & 35 & 49 \\
\hline 14 & K-14 & 5 & 28 & 20 & & & & & \\
\hline
\end{tabular}

Table 1. SPOT 6 Image Segmentation Parameter Combination in 2016

Notes: Hs: spatial radius (pixels), Hr: range radius (brightness value), M: minimum region size (pixel)

The further step of the OBIA was the classification of canopy cover and gap (see illustration on Figure 3(a)). For classifying the canopy cover and gap, then the pixel-based classification, i.e., a supervised classification using the algorithm maximum-likelihood classifier was applied. The pixel-based classification stage consisted of determining the training area and class signature. The supervised classification result is shown in Figure 3(b).

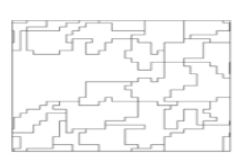

(a)

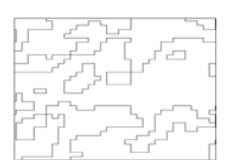

(b)

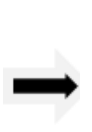

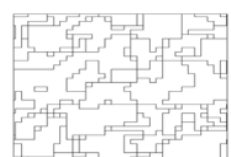

(c)

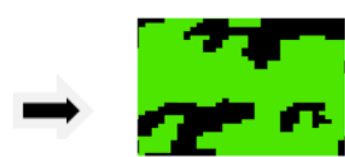

(d)

Figure 3. Steps of classification process of segmentation results; (a) results of segmentation; (b) supervised classification results; (c) overlay results of segmentation and supervissed classification results; (d) labeling of segmentation results based on supervissed classification results 


\subsubsection{Accuracy Assessment}

Some methods used in assessing the results of segmentation include using fragmentation indices [19], area fit index [20], and use of area, perimeter and shape index [21]. Accuracy analysis in this study, was assessed by using a confusion matrix principle, to provide the Overall and Kappa Accuracy. The matrix was filled out by comparing the reference data obtained from visual interpretation (on screen digitizing) and the classified image (the results of OBIA). The formulas used to calculate Overall Accuracy (OA) and Kappa Accuracy (KA) [22] are:

$$
\begin{aligned}
& \text { Overall Accuracy }(\mathrm{OA})=\frac{\sum_{i=1}^{r} X_{i i}}{N} 100 \% \\
& \operatorname{Kappa} \operatorname{Accuracy}(\mathrm{KA})=\frac{N \sum_{i=1}^{r} X_{i i}-\sum_{i=1}^{r} X_{i+} X_{+i}}{N^{2}-\sum X_{i+} X_{+i}} 100 \%
\end{aligned}
$$

where:

$\mathrm{Xii}=$ number of pixel in the diagonal element of the confusion matrix in the $\mathrm{i}$ line and $\mathrm{i}$ column, $\mathrm{Xi}+=$ total pixel (grid) in the $\mathrm{i}$ column,

$\mathrm{X}+\mathrm{i}=$ total pixel in the $\mathrm{i}$ row, $\mathrm{N}=$ total pixels

The results of the accuracy assessment for all segmentation combinations were used to select the best combination of segmentation parameters. The selection of the best segmentation results was based on the overall accuracy value and the largest kappa accuracy.

\subsubsection{Canopy cover and vegetation gap}

The measurement canopy cover in the forestry was a common work, particularly when the stand analysis was done using image analysis. In this study, the stand variable observed was canopy cover and gap of the stand. Canopy cover can be defined as the size of many leaves, twigs, branches or branches in stands that cover a certain area. While the gap in this study is interpreted as an empty area or image between branches, branches or branches in stands (Figure 4).

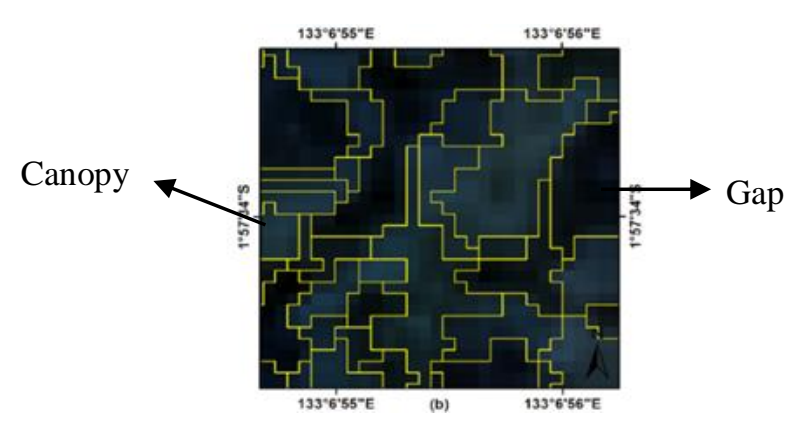

Figure 4. Differences in canopy and gap

\subsubsection{Volume estimator model}

Stand volume estimator models developed in this study express the relationship between stand volume per unit area and stand variables that could be interpreted or measured through satellite images. The model is expressed in the form of mathematical equations or regression equations. The stand variable measured from the SPOT 6 images was percent canopy cover (C) that derived based on object-based method and vegetation indices that processed using the pixel-based algorithm namely NDVI, TNDVI, SAVI, RGI, RDVI, DVI and RVI. The form of the regression model examined were:

a. Linear model : $\mathrm{V}=\mathrm{a}+\mathrm{bX}$

b. Exponential model $: \mathrm{V}=\mathrm{a} \mathrm{e}^{\mathrm{bX}}$

c. Logarithmic model $: \mathrm{V}=\mathrm{a} \cdot \ln \cdot \mathrm{X}+\mathrm{b}$

d. Polynomial model $: \mathrm{V}=\mathrm{a}+\mathrm{bX}+\mathrm{c} \mathrm{X}^{2}$

\subsubsection{Validation Model}

Validation was done intended to obtain the best model [22-25]. The validation of the estimator model was done by using half of the sample plot samples taken in the field. Validation measures that used to evaluate the models were the average deviation (SR) and aggregate deviation (SA). The average deviation is 
the percentage of the absolute value of the sum of results for the difference between the estimated value and the actual value with the estimated value of example (n). A good model would have an SR value of less than $10 \%$.

$$
\mathrm{SR}=\left[\frac{\sum_{\mathrm{i}=1}^{\mathrm{n}}\left|\frac{\sum \hat{\mathrm{y}}-\sum \mathrm{yi}}{\sum \widehat{\mathrm{yi}}}\right|}{\mathrm{n}}\right] \times 100 \%
$$

The aggregative deviation is the difference in the number of actual values with estimated values as proportional to the estimated value. A good estimation model usually has an SA value between -1 and +1 .

$$
\mathrm{SA}=\left[\frac{\sum \hat{\mathrm{y}}-\sum \mathrm{y}}{\sum \hat{\mathrm{y}}}\right]
$$

Notes:

SR : average deviation, SA : aggregate deviation, $\widehat{y} \mathrm{l}$ i estimate value, yi: i actual value, $\mathrm{n}$ :number of sample.

\section{RESULTS AND ANALYSIS}

\subsection{Volume Estimator}

\subsubsection{Volume estimator model using vegetation index}

Based on the analysis of variance, analysis of correlation and validation test, the pixel-based regression equations of each model with their associated $p$-value, $\mathrm{R}^{2}, \mathrm{SA}$ and SR are summarized in Table 2. These stand volume estimation models were developed based on several typed of vegetation indices derived from SPOT 6 images. It was shown that most of the $p$-values are less than 0.005, except model M6, M21, M24 and M27.

\begin{tabular}{|c|c|c|c|c|c|c|c|}
\hline \multirow{2}{*}{ No } & \multirow{2}{*}{$\begin{array}{l}\text { Model } \\
\text { Code }\end{array}$} & \multirow{2}{*}{ Model type } & \multirow{2}{*}{ Equation } & \multirow{2}{*}{ P-value } & \multirow{2}{*}{$\mathrm{R} 2$} & \multicolumn{2}{|c|}{ Validation measure } \\
\hline & & & & & & SA & SR \\
\hline 1 & M1 & TNDVI_exp & $\mathrm{V}=0.0000067 \mathrm{e}^{16.48 \mathrm{TNDVI}}$ & 0.000013 & 0.50 & 0.12 & 5.34 \\
\hline 2 & M2 & SAVI_exp & $\mathrm{V}=0.402 \mathrm{e}^{5.450 \mathrm{SAVI}}$ & 0.000014 & 0.49 & 0.12 & 5.37 \\
\hline 3 & M3 & NDVI_exp & $\mathrm{V}=0.402 \mathrm{e}^{8.175 \mathrm{NDVI}}$ & 0.000014 & 0.49 & 0.13 & 5.42 \\
\hline 4 & M4 & RDVI_exp & $\mathrm{V}=1.415 \mathrm{e}^{0.139 \mathrm{RDVI}}$ & 0.000020 & 0.48 & 0.13 & 5.60 \\
\hline 5 & M5 & RVI_exp & $\mathrm{V}=555.6 \mathrm{e}^{-9.38 \mathrm{RVI}}$ & 0.000011 & 0.50 & 0.13 & 5.74 \\
\hline 6 & M6 & RGI_exp & $\mathrm{V}=377.9 \mathrm{e}^{-0.78 \mathrm{RGI}}$ & 0.058481 & 0.14 & 0.07 & 7.28 \\
\hline 7 & M7 & RVI_log & $\mathrm{V}=-72.4 \ln (\mathrm{RVI})-53.57$ & 0.000011 & 0.46 & 0.14 & 8.92 \\
\hline 8 & M8 & DVI_lin & $\mathrm{V}=0.061 \mathrm{DVI}-25.63$ & 0.000030 & 0.44 & 0.14 & 9.08 \\
\hline 9 & M9 & RDVI_lin & $\mathrm{V}=3.376 \mathrm{RDVI}-42.90$ & 0.000020 & 0.45 & 0.14 & 9.49 \\
\hline 10 & M10 & SAVI_lin & $\mathrm{V}=132.9 \mathrm{SAVI}-73.82$ & 0.000014 & 0.46 & 0.14 & 9.52 \\
\hline 11 & M11 & TNDV̄I_poly & $\mathrm{V}=-5204 \mathrm{TNDVI}^{2}+10876 \mathrm{TNDVI}-5644$ & 0.000013 & 0.50 & 0.99 & 9.54 \\
\hline 12 & M12 & NDVI_lin & $\mathrm{V}=199.3 \mathrm{NDVI}-73.84$ & 0.000014 & 0.46 & 0.14 & 9.54 \\
\hline 13 & M13 & TNDVI_lin & $\mathrm{V}=401.9 \mathrm{TNDVI}-375.9$ & 0.000013 & 0.46 & 0.14 & 9.55 \\
\hline 14 & M14 & NDVI_log & $\mathrm{V}=103.0 \ln (\mathrm{NDVI})+97.44$ & 0.000014 & 0.47 & 0.14 & 9.57 \\
\hline 15 & M15 & TNDVI_log & $\mathrm{V}=405.3 \ln (\mathrm{TNDVI})+26.02$ & 0.000013 & 0.47 & 0.99 & 9.58 \\
\hline 16 & M16 & SAVI_log & $\mathrm{V}=103.0 \ln (\mathrm{SAVI})+55.67$ & 0.000014 & 0.47 & 0.14 & 9.60 \\
\hline 17 & M17 & RVI_lin & $V=-228.6 R V I+102.4$ & 0.000011 & 0.47 & 0.15 & 9.63 \\
\hline 18 & M18 & RDVI_log & $\mathrm{V}=72.80 \ln (\mathrm{RDVI})-193.3$ & 0.000020 & 0.47 & 0.15 & 9.81 \\
\hline 19 & M19 & DVI_log & $\mathrm{V}=55.90 \ln (\mathrm{DVI})-349.6$ & 0.000030 & 0.46 & 0.15 & 9.83 \\
\hline 20 & M20 & DVI_poly & $\mathrm{V}=-0.00018 \mathrm{DVI}^{2}+0.39160 \mathrm{DVI}-170.40680$ & 0.000030 & 0.51 & 0.15 & 10.04 \\
\hline 21 & M21 & RGI_lin & $\mathrm{V}=-17.52 \mathrm{RGI}+87.33$ & 0.058481 & 0.11 & 0.10 & 10.20 \\
\hline 22 & M22 & NDVI_poly & $V=-1392 N^{2} V^{2}+1630 N D V I-440.1$ & 0.000014 & 0.50 & 0.15 & 10.21 \\
\hline 23 & M23 & SAVI_poly & $V=-618.8 \mathrm{SAVI}^{2}+1087 \mathrm{SAVI}-439.9$ & 0.000014 & 0.50 & 0.15 & 10.21 \\
\hline 24 & M24 & RGI_log & $\mathrm{V}=-59.8 \ln (\mathrm{RGI})+100.8$ & 0.058481 & 0.11 & 0.10 & 10.33 \\
\hline 25 & M25 & RVI_poly & $V=-1431 . R V I^{2}+700.2 R V I-47.02$ & 0.000011 & 0.49 & 0.15 & 10.36 \\
\hline 26 & M26 & RDVI_poly & $V=-0.493 R D V I^{2}+24.43 R D V I-265.7$ & 0.000020 & 0.51 & 0.16 & 11.08 \\
\hline 27 & M27 & RGI_poly & $V=-43.84 R_{G I}^{2}+287.3 R G I-440.8$ & 0.058481 & 0.14 & 0.12 & 12.01 \\
\hline 28 & M28 & DVI_exp & $\mathrm{V}=2.868 \mathrm{e}^{0.002 \mathrm{DVI}}$ & 0.000030 & 0.47 & -0.45 & -53.10 \\
\hline
\end{tabular}

Table 2. Volume Estimator Model with SPOT 6 Image Vegetation Index in 2016

Note: Exp : exponential, Log : logarithmic, Lin : linear, Poly : polynomial

Based on the results of the significance of $p$-value and correlation value, it was found that the statistical performance of using RGI is weak, where it has a $p$-value greater than 0.05 and very low $\mathrm{R}^{2}$ of only $11 \%$. Then, it is concluded that the RGI based model could not be used for assessing the stand model. In general, the regression model developed using TNDVI, NDVI, DVI, SAVI, RDVI, and RVI have a $p$-value

Examining the object-based and pixel-based image analyses for developing stan... (Dwi Putra Apriyanto) 
below 0.05 with $\mathrm{R}^{2}$ values ranging between $11 \%$ and $51 \%$. The study results also show that the models obtained from the several forms of vegetation index have an SA values between -1 and 1 with SR less than $10 \%$. These means that the model could be statistically acceptable and implementable. Of the models, the TNDVI-based model provides the highest $\mathrm{R}^{2}$ value of $50 \%$ with excellent validation, having $\mathrm{SA}$ value of 0.12 and SR value of only $5.34 \%$, it is also shown in the estimation of pine stands using the vegetation index which shows a value of accuracy of $51 \%$ [26].

As shown in Figure 5, there are close relationships between the stand volume and the TNDVI, NDVI, DVI, SAVI, RVI, RDVI, and RGI. In general, the higher the vegetation index value tend to have the higher the volume. The TNDVI, NDVI, DVI, SAVI, and RDVI in particular the higher the vegetation index value would provide the higher the stand volume. Different trend is shown by the RGI and RVI, where the lower the vegetation index value would mean the higher the stand volume. This is due to [27] Red band and Green band values inversely proportional to the vegetation while the value is Infrared band directly proportional to the vegetation.

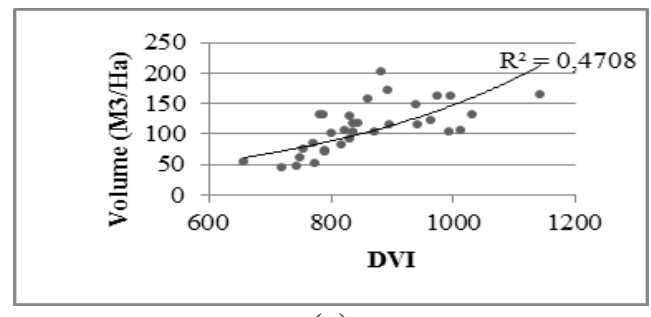

(a)

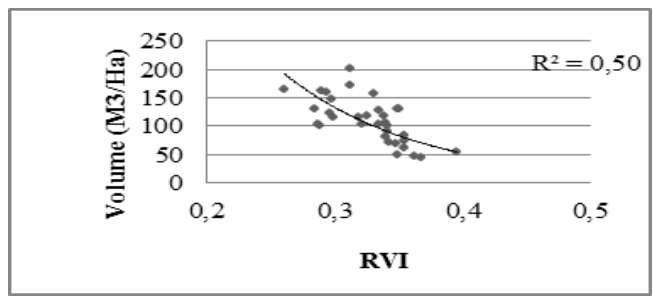

(c)

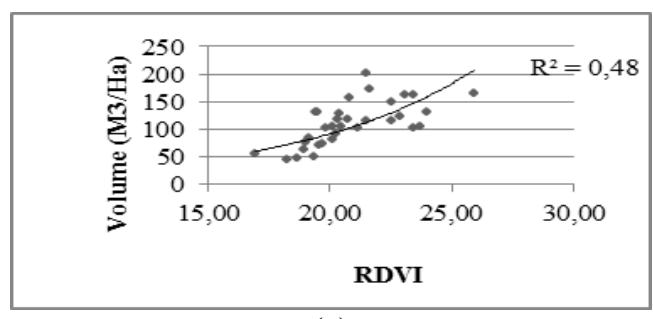

(e)

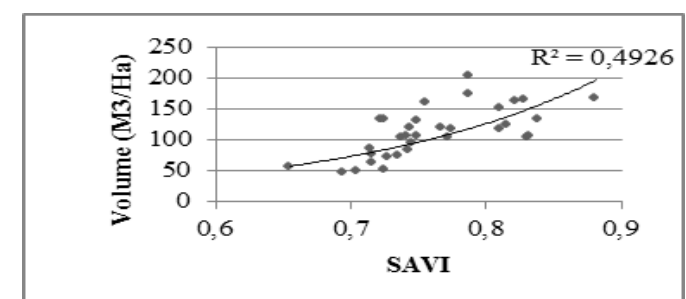

(b)

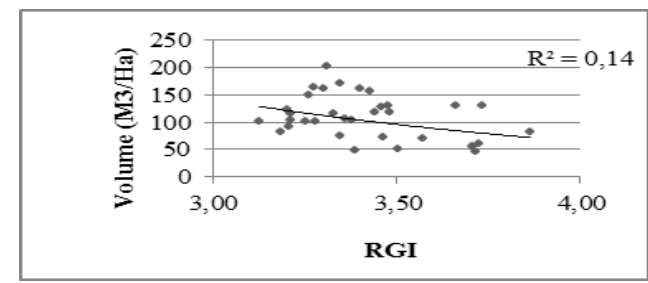

(d)

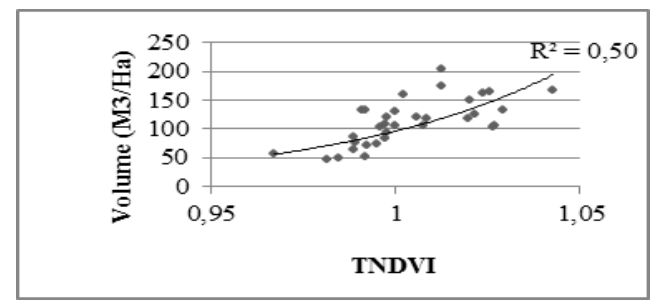

(f)

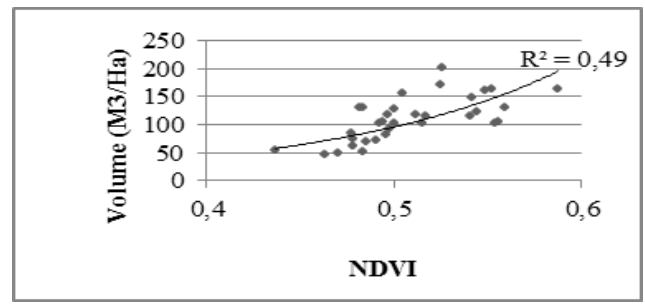

(g)

Figure 5. Scatter diagram between (a) stand volume and DVI, (b) stand volume and SAVI, (c) stand volume and RVI, (d) stand volume and RGI, (e) stand volume and RDVI,

(f) stand volume and the TNDV, (g) stand volume and the NDVI 


\subsubsection{Object-Based Volume Estimator Model}

\subsubsection{Segmentation Combination Selection}

The best combination of segmentation parameter was done by evaluating the overall accuracy value (OA) and Kappa (KA) accuracy of all segmentation combinations examined. This accuracy testis crucial to provide information regarding the coincidence between the segmentation result and actual class in the field [28]. The recapitulation of OA and KA accuracy values of parameter segmentation combination tested in this study are summarized in Figure 6. The accuracy values were obtained by comparing the results of segmentation and the results of visual interpretation and field observations as reference data.

Of the 27 tested combinations of segmentation parameters, the combination that give the highest accuracy was provided by K-10 (5-21-4), while the lowest accuracy value was in provided by K-09 (2-35-49). The Kappa and Overall accuracies of K-10 are 71.2\% and 86.6\%, while the Kappa and Overall accuracies of K-09 are $8.8 \%$ and $64.8 \%$ (Figure 6). This is in line with several previous studies which stated that the accuracy of the results of object-based classification has a fairly high value [29-32].

As shown in Figure 7, the variation of spatial radius and minimum region size did not give any significant variation of the segmentation accuracy. The significant difference of accuracy was due to the variation of range radius, where when the radius range increases then the accuracy decreases. From the overall combination of parameters, the study shows that the parameter range radius is the determinant factor that affect the detection of canopy cover and stand gap. In the best combination of parameters, the value radius range used is 21 . If the radius range is increased to 28 , then there is a decrease in the Overall accuracy value and Kappa accuracy. Different study results were shown by [11] that the most significant segmentation parameter is the minimum size region.

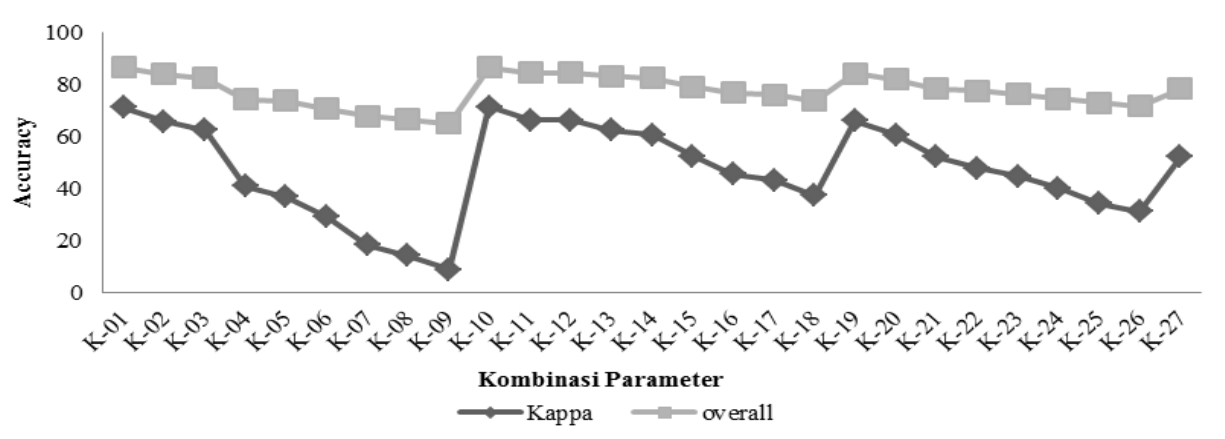

Figure 6. Value of overall accuracy and accuracy of kappa

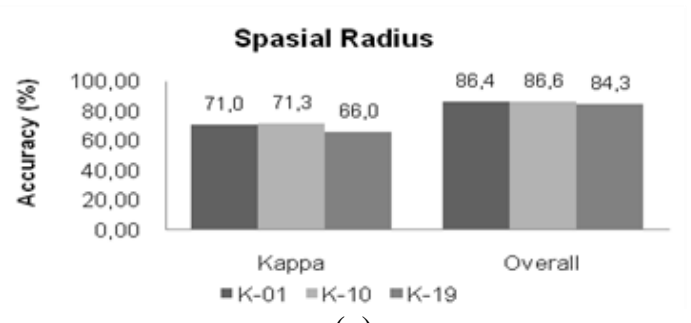

(a)

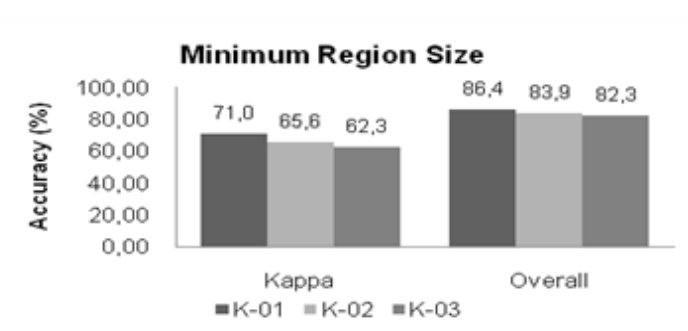

(b)

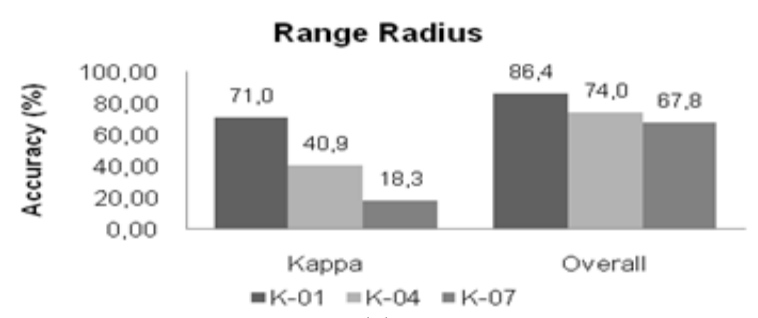

(c)

Figure 7. The Kappa and Overall accuracies for parameters (a) spatial radius, (b) minimum size region, and (c) radius range 
Figure 8 shows the results of segmentation and OBIA from SPOT6 images with a combination of K10 parameters. If observed in detail there will be differences in shape, size and the color between the gap and canopy cover. The results of image segmentation can separate canopy objects and gaps properly.

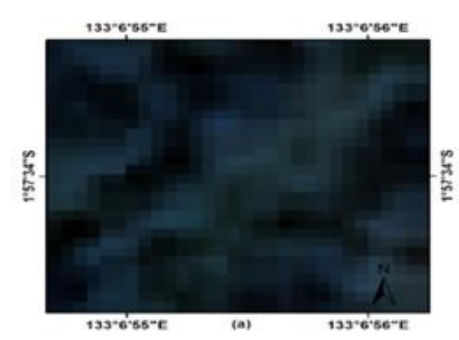

(a)

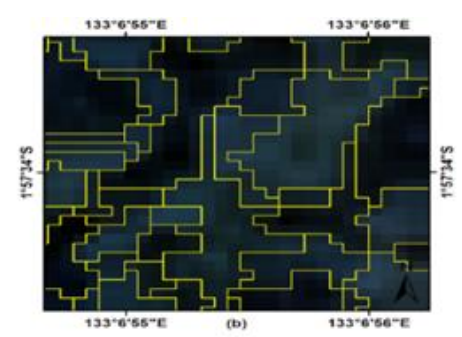

(b)

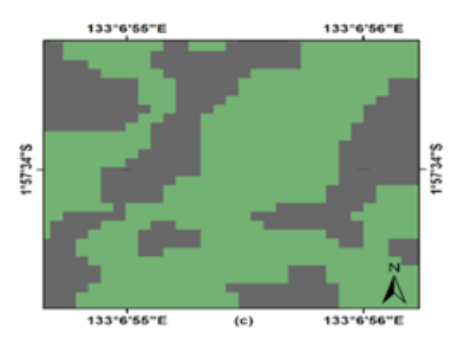

(c)

Figure 8. (a) SPOT 6 image, (b) segmentation results, and (c) OBIA results

\subsubsection{Volume estimator model with OBIA}

The percentage of canopy cover derived from the OBIA was then used to develop a stand volume estimator model. In the OBIA, the delineation of canopy and gap was obtained from the segmentation process. Furthermore, the canopy cover (percent) was the used to develop a regression model, where the response variable is standing stock per unit area.

In the plot used to construct the model, canopy cover in the image ranges from $40 \%-80 \%$ and the stand volume ranges from $40 \mathrm{~m}^{3}-200 \mathrm{~m}^{3}$ (Figure 9). Based on the results of the study, the higher the percentage of canopy cover in a digital image eat the higher the stand volume.

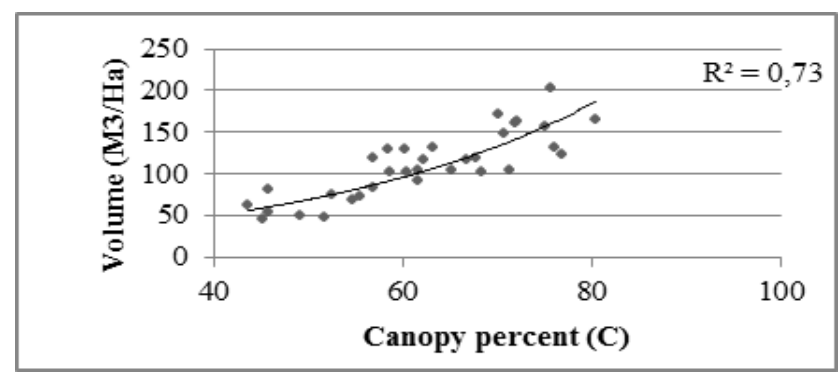

Figure 9. Scatter diagram between volume and canopy cover

From the stand volume estimator models as shown in Table 3, it is shown that the exponential model (Model code S1) is the most accurate model, having the highest $\mathrm{R}^{2}$ and the smallest SA and SR. The study found that the stand volume could be predicted using the canopy cover derived from SPOT 6. Model S1 has other factors that affect the formation of regression relationship with canopy cover volume on a relatively small image that is less than $30 \%$, it is seen from the magnitude of the coefficient of determination $\left(\mathrm{R}^{2}\right)$, which defines the biggest factor is of variables tested so this equation is worth using. Based on the equation model tested, the S1 model is the one that best meets the requirements with the aggregative deviation value (SA) being 0.16 and the average deviation (SR) is $0.92 \%$.

Table 3. Model Volume Estimator with OBIA Image SPOT 6 in 2016

\begin{tabular}{cccccccc}
\hline \multirow{2}{*}{ No } & $\begin{array}{c}\text { Code } \\
\text { Model }\end{array}$ & $\begin{array}{c}\text { Form } \\
\text { Model }\end{array}$ & \multicolumn{1}{c}{ Equation } & P-value & \multirow{2}{*}{ R2 } & \multicolumn{2}{c}{ Validation } \\
& \multicolumn{1}{c}{ SA } & & SR \\
\hline 1 & S1 & Exp & $\mathrm{V}=13.47 \mathrm{e}^{0.032 \mathrm{C}}$ & 0.00000000068 & 0.73 & 0.16 & 0.92 \\
2 & S2 & Log & $\mathrm{V}=194.9 \ln (\mathrm{C})-692.1$ & 0.00000000068 & 0.71 & 0.18 & 5.91 \\
3 & S3 & Lin & $\mathrm{V}=3.257 \mathrm{C}-92.28$ & 0.00000000068 & 0.71 & 0.17 & 4.67 \\
4 & S4 & Poly & $\mathrm{V}=-0.0030 \mathrm{C}^{2}+3.6257 \mathrm{C}-103.3021$ & 0.00000000068 & 0.71 & 0.18 & 5.79 \\
\hline
\end{tabular}

Note: Exp : exponential, Log : logarithmic, Lin : linear, Poly : polynomial 


\subsection{Map of Volume Distribution}

From the selected models, then a spatial volume distribution of stand volume was made.

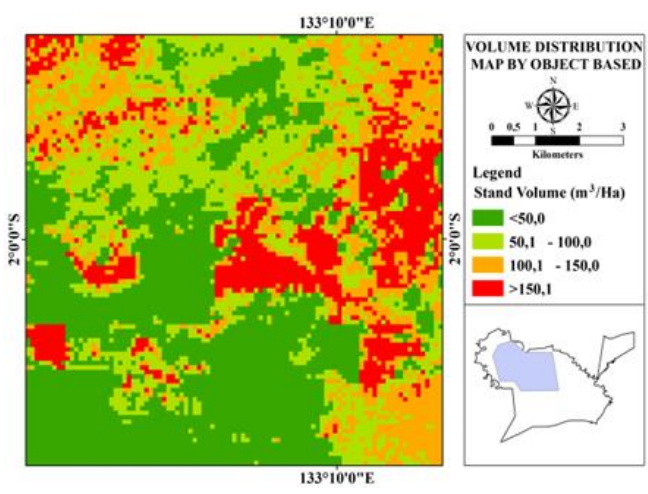

Figure 10. Stand volume derived by the OBIA

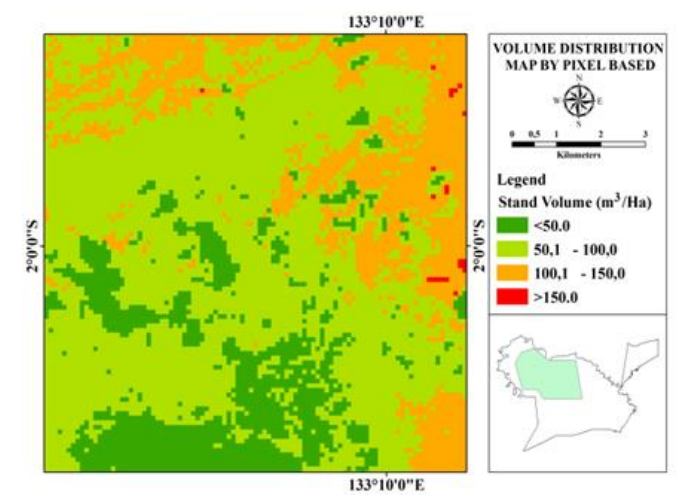

Figure 11. Stand volume derived by the pixel-based

\section{CONCLUSION}

Object-based image analysis (OBIA) with a mean-shift algorithm could detect and identify canopy cover and gap of low land forest accurately, having accuracy OA of $73 \%$ and KA of $86 \%$. The stand volume estimator model using canopy cover derived from the OBIA is significantly more accurate than those model developed using vegetation indices derived from the pixel-based approach. The estimator model with the OBIA approach is $\mathrm{V}=13.47 \mathrm{e}^{0.032 \mathrm{C}}$ which has $\mathrm{SA}=0.16$ and SR on only $0.92 \%$ less than $1 \%$ while the estimator model with the vegetation index approach is $\mathrm{V}=0.0000067 \mathrm{e}^{16.48 \mathrm{TNDVI}}$ with $\mathrm{SA}$ values $=0.12$ and $\mathrm{SR}=5.34 \%$.

\section{REFERENCES}

[1] R. E. McRoberts, et al., "The effects of imperfect reference data on remote sensing-assisted estimators of land cover class proportions," ISPRS Journal of Photogrammetry and Remote Sensing, vol. 142, pp. 292-300, Aug 2018.

[2] M. Pulkkinen, et al., "Stereo-imagery-based post-stratification by regression-tree modelling in Swiss National Forest Inventory," Remote Sensing of Environment, vol. 213, pp. 182-194, Aug 2018.

[3] R. E. McRoberts, et al., "Using a remote sensing-based, percent tree cover map to enhance forest inventory estimation," Forest Ecology and Management, vol. 331, pp. 12-18, Nov 2014.

[4] D. Stojanova, et al., "Estimating vegetation height and canopy cover from remotely sensed data with machine learning," Ecological Informatics. vol. 5, pp. 256-266, Jul 2010.

[5] K. Humagain, et al., "Estimating forest canopy cover dynamics in Valles Caldera National Preserve, New Mexico, using LiDAR and Landsat data," Applied Geography, vol. 99, pp. 120-132, Oct 2018.

[6] D. Phiri, et al., "Effects of pre-processing methods on Landsat OLI-8 land cover classification using OBIA and random forests classifier," International Journal of Applied Earth Observation and Geoinformation, vol. 73, pp. 170-178, Dec 2018.

[7] T. Liu and A. A. Elrahman, "Multi-view object-based classification of wetland land covers using unmanned aircraft system images," Remote Sensing of Environment, vol. 216, pp. 122-138, Oct 2018.

[8] W. Zhongmin and D. Shanjia, "Mean-Shift Algorithm for 3D Spatial Positioning," Procedia Computer Science, vol. 131, pp. 446-453, 2018.

[9] Z. Shuang and P. Y. Ping, "Mean-Shift Algorithm Apply for Infrared Imaging Tracking," AASRI Procedia, vol. 1, pp. 52-57, 2012.

[10] T. G. Peng, et al., "Mean shift algorithm equipped with the intersection of confidence intervals rule for image segmentation,” Pattern Recognition Letters, vol. 28, pp. 268-277, Jan 2007.

[11] R. P. Silalahi, et al., "Assessing the Crown Closure of Nypa on UAV Images using Mean -Shift Segmentation Algorithm," Indonesian Journal of Electrical Engineering and Computer Science, vol. 9, pp. 722-730, 2018.

[12] D. Ballari, et al., "UAV monitoring for enviromental management in galapagos Island," The International Archives of the Photogrammetry, Remote Sensing and SpatialInformation Sciences, vol. XLI-B1, pp. 1105-1111, Jun 2016.

[13] B. Aiazzi, et al., "Nonparametric change detection in multitemporal SAR images based on mean-shift clustering," IEEE Transactions on Geoscience and Remote Sensing, vol. 51, pp. 2022-2031, Apr 2013.

[14] N. Chehata, et al., "Object-based change detection in wind storm-damaged forest using high resolution multispectral images," International Journal of Remote Sensing, vol. 35, pp. 4758-4777, Jul 2014.

[15] N. M. Farda, "Klasifikasi berorientasi obyek berdasarkan segmentasi untuk analisis citra penginderaan jauh resolusi spasial tinggi," Master thesis, Yogyakarta: Gadjah Mada University, 2008. 
[16] L. Lalaoui, et al., "New method for image segmentation," Procedia-Social dan Behavioral Sciences, vol. 195, pp. 1971-1980, 2015.

[17] P. Danoedoro, "Pengantar pencideraan jauh digital," Penerbit ANDI, Yogyakarta, Jun 2012.

[18] H. Krisnawati, et al., "Monograf model-model alometrik untuk pendugaan biomassa pohon pada berbagai ekosistem hutan di Indonesia," Pusat penelitian dan pengembangan konservasi dan rehabilitasi Badan penelitian dan pengembangan kehutanan, Bogor (ID), 2012.

[19] K. C. Strasters and J. J. Gerbrands, "Three-dimensional image segmentaion using a split, merge and group approach," Pattern Recognition Letter, vol. 12, pp. 307-325, May 1991.

[20] A. Lucieer, "Uncertainties in segmentation and their visualisation," PhD thesis, Utrecht (NL): Utrecht University, 2004.

[21] M. Neubert, et al., "Object-Based Image Analysis - Assessingimage segmentation quality - concepts, methods and application,” Springer, pp. 769-784, Jan 2008.

[22] I. N. S. Jaya, “Analisis Citra Digital, Perspektif Penginderaan Jauh untukPengelolaan Sumberdaya Alam,” Bogor (ID): Institut Pertanian Bogor, 2015.

[23] I. N. S. Jaya and S. Kobayashi, "Classification of detailed forest cover types based upon the separability algorithm: a case study in the Yahiko Mountain and Shibata Forest Area," Journal of the Remote Sensing Society of Japan, vol. 15, pp. 40-53, 1995.

[24] R. Kumar, et al., "Forest cover dynamics analysis and prediction modeling using logistic regression model," Ecological Indicators, vol. 45, pp. 444-455, 2014.

[25] H. Muis, et al., "Information required forestimating the indicator of forest reclamation success in ex coal-mining area," Indonesian Journalof Electrical Engineering and Computer Science (IJEECS), vol. 3, pp. 182-193, Jul 2016.

[26] H. Yusuf and S. H Murti, "Aplikasi citra alos AVNIR-2 untuk estimasi volume tegakan pinus di wilayah kopeng," Jurnal Bumi Indonesia, vol. 4, 2015.

[27] C. J. Tucker, "Red and photographic infrared linear combination for Monitoring vegetation," Remote Sensing of Environment, vol. 8, pp. 127-150, May 1979.

[28] H. Costa, et al., "Supervised methods of image segmentation accuracy assessment in land covel mapping," Remote Sensing for Environment, vol. 205, pp. 338-351, 2018.

[29] V. Lebourgeois, et al., "A Combined random forest and OBIA classification scheme for mapping smallholder Agriculture at different nomenclature levels using multisource data (simulated sentinel-2 time series, CHRS and DEM)," Remote sensing, vol. 9, pp. 2072-4292, Mar 2017.

[30] A. S. Laliberte and A. Rango, "Texture and Scale in Object-Based Analysis of Subdecimeter Resolution Unmanned Aerial Vehicle (UAV) Imagery," IEEE Transactions Geoscience and Remote Sensing, vol. 47, pp. 761-770, 2017.

[31] A. Chakraborty, et al., "A reflection om image classifications for forest ecology Management: towards lanscape mapping and Monitoring," Academic press, handbook of neural computation, pp. 67-85, 2017.

[32] M. Hussain, et al., "Change detection from remotely sensed images: from pixel based to object-based approaches," ISPRS jurnal of photogrammetry and remote sensing, vol. 80, pp. 91-106, Apr 2013.

\section{BIOGRAPHIES OF AUTHORS}
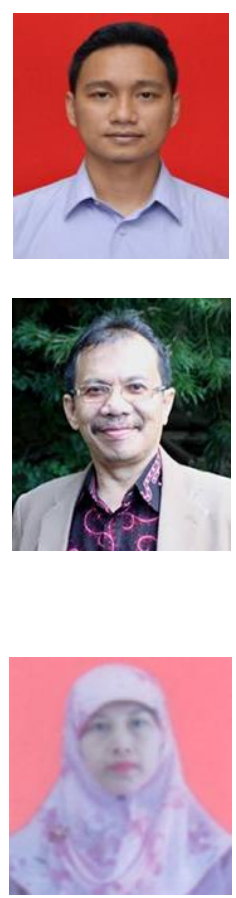

Dwi Putra Apriyamto a graduate student of Forest Management Science, Graduate School of Halu Oleo University. His research interest is in remote sensing and image segmentation to support forest planning activity. He got his bachelor degree of forestry in 2015 from Forest Management, Faculty of Forestry and Enviromental Science, Halu Oleo University.

Prof. Dr. I NengahSurati Jaya is a permanent professor of forest planning since 2007at Bogor Agricultural University, majoring in remote sensing and spatial geoscience. Since 1990, he has numerous researches, publications and works related to the remote sensing and spatial modelling in the forestry and environmental related sectors. Recently, his research has been focused on the applied science on the use high resolution images, terrestrial data and fisheye camera to develop practical method as well as algorithm to support a sustained forest management. He got his $\mathrm{PhD}$ in1996 from Niigata University, Master'sdegree in 1993 from Graduate School of Environmental Science, Niigata University, bachelor's of forestry in1985 from Forest Management Department, Faculty of Forestry, Bogor Agricultural University.

Dr. Nining Puspaningsih is a permanent associate professor at the Forest Management Department, Faculty of Forestry, Bogor Agricultural University. Her special interest is in the field of remote sensing and GIS in forest management. He got his PhD in 2011 from Bogor Agricultural University, Master of Sciences in 1997 from Graduate School of Bogor Agricultural University and bachelor degree in 1988 from Gadjah Mada University. 